\title{
Avidity of antibodies against released proteins of Yersinia spp: comparison of patients with or without reactive arthritis
}

\author{
RIITTA LAHESMAA-RANTALA, ${ }^{1}$ JÜRGEN HEESEMANN, ${ }^{3}$ \\ OLLI-PEKKA LEHTONEN, ${ }^{1}$ KAISA GRANFORS, ${ }^{1}$ AND AULI TOIVANEN 2 \\ From the Departments of ${ }^{1}$ Medical Microbiology and ${ }^{2}$ Medicine, University of Turku, Turku, Finland; and \\ ${ }^{3}$ Institut for Medical Microbiology and Immunology, University of Hamburg, Hamburg, West Germany
}

SUMmarY The avidity of IgM, IgG, and IgA class antibodies against virulence plasmid encoded proteins of yersinia, so called released proteins (RPs), was studied in the serum samples of 22 patients with yersinia triggered reactive arthritis and 22 with uncomplicated yersiniosis. The avidity of anti-RP antibodies did not differ significantly between the patient groups, even though the total amount of IgA class anti-RP antibodies was significantly higher in patients with arthritis than in those with uncomplicated yersiniosis at the early stage of infection. Earlier results with whole bacterial extracts or lipopolysaccharide as the antigens have shown an increased avidity of IgA class anti-yersinia antibodies in patients with yersinia triggered reactive arthritis. This phenomenon was not observed in antibody response against RPs, and thus production of these proteins seems unimportant at later stages of infection for the yersinia organisms stimulating the persisting and maturing antibody response in the yersinia triggered reactive arthritis.

$Y$ enterocolitica and $Y$ pseudotuberculosis grown at $37^{\circ} \mathrm{C}$ produce several virulence plasmid encoded proteins. ${ }^{12}$ Moreover, plasmid bearing $Y$ enterocolitica and $Y$ pseudotuberculosis release into calcium deficient media proteins, so called released proteins (RPs), which are immunologically related to yersinia outer membrane proteins. ${ }^{34}$ These proteins are expressed in vivo as both patients and animals produce specific antibodies against them during yersinia infection. ${ }^{256}$

It is not known why some patients develop reactive arthritis after acute yersiniosis, whereas others recover without any complications after the infection. Development of reactive arthritis is associated with the tissue antigen HLA-B2 $7^{7}$ and certain immunological features. ${ }^{8} 9$ Patients who develop yersinia triggered reactive arthritis are characterised by strong and persisting IgA antibody response against yersinia. ${ }^{10-12}$ Analysis of antibody avidity has shown that patients with reactive arthritis have significantly more high avidity IgA class antibodies than those with uncomplicated infection, - a difference which increases with time. ${ }^{13}$ This was

Accepted for publication 13 March 1989.

Correspondence to Dr Riitta Lahesmaa-Rantala, Department of Medical Microbiology, University of Turku, SF-20520 Turku, Finland. seen by using a bacterial extract and separately, purified lipopolysaccharide of $Y$ enterocolitica $0: 3$ as the antigen. In this study of the role of RPs in the pathogenesis of reactive arthritis we investigated avidity of the anti-RP antibody response in patients with and without yersinia triggered reactive arthritis.

\section{Patients and methods}

PATIENTS AND SERUM SAMPLES

The avidity of anti-yersinia antibodies was studied in the serum samples of 44 patients with recent yersiniosis. Diagnosis was based on the clinical picture, clearly increased levels of anti-yersinia antibodies detected by enzyme linked immunosorbent assay (ELISA), ${ }^{14}$ and in 15 cases, additionally, by isolation of the pathogen from the stools. Twenty two patients (age 37 (SD 13) years, 14 men, eight women) developed reactive arthritis as a complication after infection and the other 22 (age 29 (11) years, 13 men, nine women) had uncomplicated yersiniosis. Two samples from each patient were studied; one taken at less than two months and another at about six months after onset of the infection. Serum pairs from the two patient groups were chosen so that the time interval after onset of 
infection differed by only $2 \cdot 6$ (SD $2 \cdot 1$ ) days between each pair.

\section{A N T I GENS}

The bacterial strain used for production of RPs was $Y$ enterocolitica serotype 0:8 (WA-314 $\mathrm{Nal}^{\mathrm{r}}$, containing the $\mathbf{4 2}$ megadalton virulence plasmid). Isolation and analysis of the proteins have been described recently in detail. ${ }^{3}$ Briefly, bacteria were first grown in BHI broth at $37^{\circ} \mathrm{C}$ for 90 minutes, followed by incubation under calcium restriction by addition of $10 \mathrm{mM}$ magnesium-EGTA (ethyleneglycolbis (aminoethylether)tetra-acetate) for an additional 90 minutes. The bacteria were removed by centrifugation and the proteins precipitated from culture supernatant by ammonium sulphate followed by three washings of the insoluble protein precipitate with water. Analysis of the RPs by sodium dodecyl sulphate-polyacrylamide gel electrophoresis (SDS-PAGE) and immunoblotting and purity controls was performed as described earlier. ${ }^{3}$

\section{ELISA FOR ANTI-RP ANTIBODIES}

An ELISA for anti-yersinia antibodies was performed as described earlier. ${ }^{14}$ The polystyrene microtitre plates (Titertek, Flow Laboratories, Scotland) were coated with $6 \mu \mathrm{g} / \mathrm{ml}$ of RPs in phosphate buffered saline $(0.1 \mathrm{M}, \mathrm{pH} 7.5)$ by overnight incubation at $37^{\circ} \mathrm{C}$, and saturated with $1 \%$ normal sheep serum in phosphate buffered saline. Optimal dilutions were chosen to be on the log-linear part of the antibody dilution curves. Thus serum samples taken at six months were diluted twofold from 1:20 onwards for IgA, IgM, and IgG. Serum samples taken at 0-2 months were diluted from 1:160 onwards for IgM and from 1:320 onwards for IgG. Samples were incubated on the plates for two hours at $37^{\circ} \mathrm{C}$ and the plates were washed three times with $0.9 \%$ saline containing $0.05 \%$ Tween 20 . Alkaline phosphatase conjugated antihuman IgM, IgG, and IgA (Orion Diagnostica, Helsinki, Finland) were added and incubated on the plates overnight at room temperature (the specificity of these antihuman antibodies had been confirmed previously ${ }^{13}$ ). The plates were washed, substrate added, and after an enzyme reaction of $\mathbf{3 0}$ minutes at $37^{\circ} \mathrm{C}$ the optical density was measured at a wavelength of $405 \mathrm{~nm}\left(\mathrm{OD}_{\mathbf{4 0 5}}\right)$. A blank $O D_{405}$ given by buffer alone was subtracted from the $\mathrm{OD}_{405}$ values of the samples.

DETERMINATION OF ANTIBODY AVIDITY Different antibody dilutions with a constant amount of antigen were used to construct a dose-response curve for each sample, and the curves were analysed by a computerised curve fitting method. ${ }^{15}$ The method gives in arbitrary units two variables, which indicate the amount of antibodies binding either in: antibody or antigen excess. The estimate of highs avidity antibodies reflects the amount of antibodieso binding as extrapolated antibody excess-that is $\mathrm{OD}_{405}$ of undiluted sample - and the estimate of the total amount of specific antibodies gives the end point titre at a cut off level of $\mathrm{OD}_{405}=0.05 \mathrm{Q}$ indicating the amount of antibodies binding in" antigen excess. It has been shown experimentally $\vec{\rho}$ that these estimates do correlate with the amount of high avidity antibodies and the total amount of antigen specific antibodies respectively. ${ }^{15} 16$

For evaluation of the specificity and sensitivity of the avidity determinations the following propertieso of yersinia RPs are relevant: (a) all patients with yersinia infection develop antibodies against $\operatorname{RPs}^{5} \overrightarrow{0}$ (b) RPs of different serotypes of enteropathogeni\& yersiniae are serologically closely related (commono virulence associated antigens ${ }^{3}$ ); (c) purified RPs. contain insignificant amounts of lipopolysaccharides $\left(<0.5 \mu \mathrm{g} / \mathrm{mg}\right.$ protein $\left.{ }^{3}\right) ;(d)$ the residual reactivity of serotype $0: 3$ specific anti-lipopolysaccharide anti $\frac{\Phi}{3}$ bodies with traces of lipopolysaccharide in RP preฮ paration can be excluded by using RPs isolated frem $Y$ enterocolitica serotype $\mathrm{O}: 8 ;(e)$ serotype strains are common in the United States but are rare in Finland; there is no cross reactivity between antigens of serotypes $0: 8$ and $0: 3 .{ }^{17}$
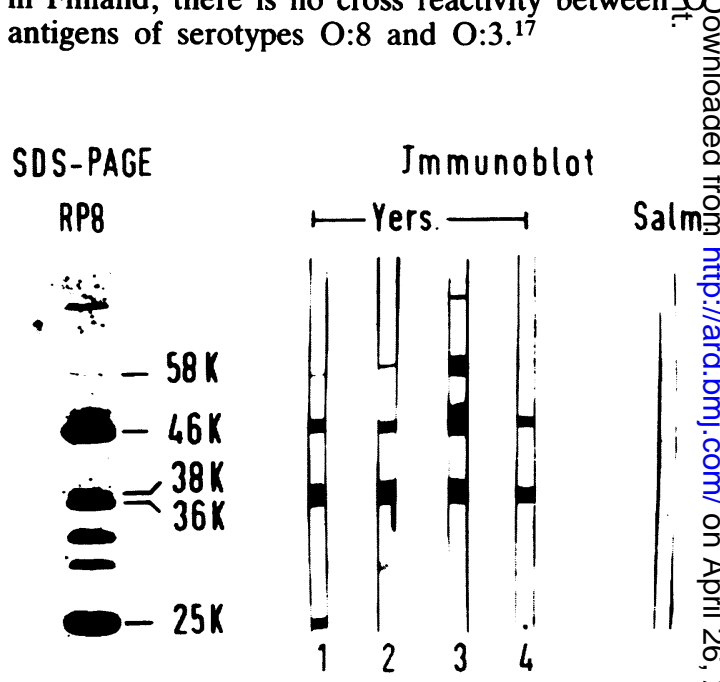

Fig. 1 Left: Coomassie stained band pattern of released proteins (RPs) of $Y$ enterocolitica serotype $O: 8$ obtained by $\omega$ sodium dodecyl sulphate-polycrylamide gel electrophoresis (SDS-PAGE) (11\%); the molecular weights of the major antigenic proteins are denoted as kilodaltons. Right: IgG immunoblot patterns of representative patients with yersinia infection (1-4). Salm: IgG immunoblot showing noreactivity against $R P$ s with serum of a patient suffering from Salmonella typhimurium infection (negative control). 
S T A T IS T I CS

Patient groups were compared using linear discriminant analysis. ${ }^{18}$

\section{Results}

\section{A N T IGENS}

Analysis of RPs on SDS-PAGE and immunoblotting (Fig. 1) shows that RPs are recognised by serum samples from patients with yersinia infection and not by serum from a patient with salmonella infection.

TOTAL AMOUNT OF ANTI-RP ANTIBODIES At the early stage of infection the total amount of IgA class anti-RP antibodies was significantly higher in patients with arthritis than in those with uncomplicated yersiniosis $(\mathrm{p}<0.0001$, Table 1). Such a difference was not seen in the samples taken at six months after onset of the infection. The total amount of IgM and IgG class anti-RP antibodies did not differ between the patient groups.

\section{AVIDITY OF ANTI-RP ANTIBODIES}

The avidity of anti-RP antibodies did not differ significantly in patients with or without yersinia triggered reactive arthritis. This was true for all three immunoglobulin isotypes and for samples taken at the early and later stages of the infection. Whereas the avidity of $\operatorname{IgA}$ and IgG antibodies was lower in the six months' samples than in those taken at two months, the avidity of IgM anti-RP antibodies increased with time; the increase was observed in both patient groups (Table 1). The results were the same whether the antigen was used at a concentration of $6 \mu \mathrm{g} / \mathrm{ml}$ or in a 1:50 dilution of that.

\section{Discussion}

We have recently shown that the difference in $\operatorname{IgA}$ response between patients with or without yersinia triggered reactive arthritis concerns predominantly antibodies of high avidity. ${ }^{13}$ This result was obtained with bacterial cell extracts or lipopolysaccharide. In this study the avidity against RPs of $Y$ enterocolitica was investigated. Owing to the antigenic similarity between RPs of Yersinia spp, antibodies raised against the RPs of $Y$ enterocolitica $\mathrm{O}: 3$ react equally well with the RPs of $Y$ enterocolitica $\mathrm{O}: \mathrm{8}^{3^{3}}$ To exploit this fact $Y$ enterocolitica $0: 8$ was chosen as the source of RPs, thereby excluding the influence of serotype $\mathrm{O}: 3$ specific anti-lipopolysaccharide antibodies on the results.

In constrast with our earlier studies using other antigens, this study did not show any differences in the avidity of anti-RP antibodies between the two patient groups either at the early stage of the infection or at six months. The total amount of $\operatorname{IgA}$ class anti-RP antibodies was significantly higher in patients with arthritis, however, than in those with uncomplicated yersiniosis at the early stage of the infection $(\mathrm{p}<0.0001)$. Furthermore, our previous results indicated that the avidity of IgA class antibodies against yersinia lipopolysaccharide decreased less in patients with arthritis than in those without arthritis. ${ }^{13}$ This was not observed in antibody response against RPs. In fact, as estimated by $\mathrm{OD}_{405}$ values, most patients had a considerably decreased level of $\operatorname{IgA}$ antibodies against RPs at six months in comparison with either the level at the start of the disease or the level against lipopolysaccharide at six months (data not shown). An explanation could be that RPs are functionally important for the bacteria invading tissues and trying to escape the

Table 1 Estimates of serum total specific (ETSA) and high avidity (EHAA) anti-yersinia antibodies against 'released proteins' in serum samples of patients with $(A+)$ and without reactive arthritis $(A-)$ after recent yersinia infection. Values are means (SD) in arbitrary units

\begin{tabular}{|c|c|c|c|c|c|c|}
\hline \multirow{2}{*}{$\begin{array}{l}\text { Antibody } \\
\text { class }\end{array}$} & \multicolumn{3}{|l|}{ a-2 Months } & \multicolumn{3}{|l|}{6 Months } \\
\hline & $A+$ & $A-$ & $p$ & $A+$ & $A-$ & $p$ \\
\hline \multicolumn{7}{|l|}{$E T S A^{*}$} \\
\hline IgM & $3.49(0.38)$ & $3.26(0 \cdot 26)$ & $0 \cdot 6$ & $2 \cdot 53(0 \cdot 25)$ & $2.57(0.19)$ & 0.7 \\
\hline IgG & $3.94(0.52)$ & $3.62(0.34)$ & 0.07 & $3.41(0.23)$ & $3.39(0.14)$ & 0.9 \\
\hline IgA & $3.98(0.31)$ & $3.28(0.65)$ & 0.00002 & $2.36(0.38)$ & $2.27(0.48)$ & $0 \cdot 8$ \\
\hline \multicolumn{7}{|l|}{$E H A A$} \\
\hline IgM & $1.09(0.67)$ & $0.80(0.54)$ & $0 \cdot 1$ & $1.25(0.47)$ & $1.43(0.35)$ & $0 \cdot 2$ \\
\hline IgG & $1.33(0.40)$ & $1.10(0.43)$ & $0 \cdot 8$ & $0.79(0.33)$ & $0.77(0.29)$ & $1 \cdot 0$ \\
\hline IgA & $0.65(0.31)$ & $0.57(0.48)$ & $0 \cdot 1$ & $0.30(0.15)$ & $0.26(0.20)$ & 0.5 \\
\hline
\end{tabular}

*The number of patients in both groups was 22 at $0-2$ months and 18 at 6 months. 


\section{Lahesmaa-Rantala, Heesemann, Lehtonen, Granfors, Toivanen}

host's defence mechanisms-that is, at the early stage of the infection. Plasmid encoded outer membrane proteins of yersinia are known to increase the serum resistance of bacteria ${ }^{19}$ and the ability to resist $\mathrm{C} 3 \mathrm{~b}$ mediated phagocytosis by granulocytes. ${ }^{20}$ Thus the increased anti-RP $\operatorname{IgA}$ in arthritic patients might reflect the increased production of RPs. This view is also concordant with the finding that high concentrations of antigen favour formation of low avidity antibodies. ${ }^{21}$ Large amounts of RPs are released when plasmid bearing yersiniae grow at $37^{\circ} \mathrm{C} .^{3}$

Altogether, these results indicate that at the early phase of disease patients with reactive arthritis have an increased level of IgA class antibodies against RPs, probably reflecting increased RP production by the bacteria invading the host tissues. At the later stages of the infection secretion of RPs seems not to be important for the yersinia organisms persisting in the host.

We thank Mrs Annika Inna for excellent technical assistance. This study was supported by the Sigrid Jusélius Foundation and the Yrjö Jahnsson Foundation.

\section{References}

1 Skurnik M. Expression of antigens encoded by the virulence plasmid of Yersinia enterocolitica under different growth conditions. Infect Immun 1985; 47: 183-90.

2 Bölin I, Portnoy D A. Wolf-Watz H. Expression of the temperature-inducible outer membrane proteins of yersiniae. Infect Immun 1985; 48: 234-40.

3 Heesemann J, Gross U, Schmidt N, Laufs R. Immunochemical analysis of plasmid-encoded proteins released by enteropathogenic Yersinia sp. grown in calcium-deficient media. Infect Immun 1986; 54: 561-7.

4 Forsberg $\AA$, Bölin I, Norlander L, Wolf-Watz H. Molecular cloning and expression of calcium-regulated, plasmid-coded proteins of $\mathrm{Y}$. pseudotuberculosis. Microbiology and Pathogenesis 1987; 2: 123-37.

5 Heesemann J, Eggers C, Schröder J. Serological diagnosis of yersiniosis by immunoblot technique using virulence-associated antigen of enteropathogenic yersiniae. Contrib Microbiol Immunol 1987; 17: 285-9.

6 Ståhlberg T H, Granfors K. Toivanen A. Immunoblot analysis of human IgM, IgG and IgA response to plasmid-encoded anti- gens of Yersinia enterocolitica serovar 03. J Med Microbiभ̆ 1987; 24: 157-63.

7 Aho K, Ahvonen P. Lassus A, Sievers K. Tiilikainen A. HLA A27 in reactive arthritis. A study of yersinia arthritis ang Reiter's disease. Arthritis Rheum 1974; 17: 521-6.

8 Toivanen A. Granfors K, Lahesmaa-Rantala R, Leino $\frac{\mathrm{R}}{\mathrm{O}}$ Ståhlberg $T$, Vuento R. Pathogenesis of yersinia-triggere reactive arthritis. Immunological, microbiological and clinic aspects. Immunol Rev 1985; 86: 47-70.

9 Toivanen A, Toivanen P. Pathogenesis of reactive arthritis. I Toivanen A, Toivanen P, eds. Reactive arthritis. Boca Raton. Florida: CRC Press, 1988: 167-78.

10 Granfors K. Viljanen M, Tiilikainen A, Toivanen A. Persistence of IgM, IgG and $\operatorname{IgA}$ antibodies to yersinia and yersinim arthritis. J Infect Dis 1980; 141: 424-9.

11 Granfors K. Toivanen A. IgA-anti-yersinia antibodies मी yersinia triggered reactive arthritis. Ann Rheum Dis 1986; 49 . 561-5.

12 Toivanen A, Lahesmaa-Rantala R, Vuento R, Granfors K. Association of persisting $\operatorname{IgA}$ response with yersinia triggered $\mathrm{P}$ reactive arthritis: a study on 104 patients. Ann Rheum Dis 1987 46: 898-901.

13 Lahesmaa-Rantala R, Lehtonen O-P, Granfors K, Toivane A. Avidity of anti-yersinia antibodies in yersiniosis patients with and without yersinia-triggered reactive arthritis. Arthritise Rheum 1987: 30: 1176-81.

14 Granfors K. Measurement of immunoglobulin M (IgM), Ig\& and IgA antibodies against Yersinia enterocolitica by enzym® linked immunosorbent assay: persistence of serum antibodieg during disease. J Clin Microbiol 1979; 9: 336-41.

15 Lehtonen O-P, Viljanen M K. A binding function for curpyefitting in enzyme-linked immunosorbent assay (ELISA) ang $i \vec{E}$ use in estimating the amounts of total and high affinity bodies. Int J Biomed Comput 1982; 13: 471-9.

16 Lehtonen O-P. Eerola E. The effect of different antitity affinities on ELISA absorbance and titer. J Immunol Method 1982; 54: 233-40.

17 Thomas L V, Gross R J, Cheasty T, Shipp C R, Rowe B. Ant? genic relationships among type strains of Yersinia enterocoliticån and those of Escherichia coli, Salmonella spp. and Shigella sppo J Clin Microbiol 1983; 17: 109-11.

18 Armitage P. Statistical methods in medical research. 3rd ed Oxford: Blackwell Scientific, 1974: 302-40.

19 Pai C H, deStephano L. Serum resistance associated witg virulence in Yersinia enterocolitica. Infect Immun 1982; 35 605-11.

20 Tertti R, Eerola E, Lehtonen O-P, Ståhlberg T H, Viander M Toivanen A. Virulence-plasmid is associated with the inhibition of opsonization in Yersinia enterocolitica and Yersinia pseudos tuberculosis. Clin Exp Immunol 1987; 68: 226-74.

21 Mond J, Kim Y T. Siskind G W. Studies on the control of antS body synthesis. V. Effect of nonspecific modification of the magnitude of the immune response on the affinity of the antibody synthesized. J Immunol 1974: 112: 1255-63. 